\title{
Do drug advertisements provide therapeutic information?
}

\author{
Gerry V Stimson Addiction Research Unit, Institute of Psychiatry, London
}

In this study of advertisements appearing in medical periodicals and by direct mail advertising to general practitioners, Dr Stimson, a sociologist, concludes that from what is intended to provide therapeutic information hardly any therapeutic information is provided. He reminds the reader of the safeguards which surround all drug advertising by law and by the code of practice of the Association of the British Pharmaceutical Industry but these safeguards do not appear to control real or potential sins of omission. Frequently in these advertisements the literature relating to the drug is quoted but Dr Stimson found that it was difficult to trace all the papers quoted in different types of medical library. (Some references quoted were to unpublished papers but surely the blame should be shared in this situation?) Dr Stimson also gives a vivid and fascinating glimpse of what he calls the 'images and stereotypes' of the patients who, it is claimed, would benefit from the drug being advertised. Certainly most general practitioners must be aware that when they prescribe that image is displaced by an individual but the portrait gallery is indeed depressing. However, to balance these advertisements drug companies issue data sheets which must be more informative than advertisements and conform to regulations in their format. Unfortunately data sheets are only issued every 15 months whereas the 'average general practitioner is potentially exposed to 1300 advertisements every month'. In other words, the data sheet and not the advertisement should be the guideline but it arrives too infrequently to offset the lack of therapeutic information contained in advertisements.

All medical practitioners have the problem of keeping up to date with newly introduced drugs. Although the number of significant chemotherapeutic advances may be as few as five each year, the number of new drug products appearing each year is in the region of 200 . The average market life of a drug, from the time of its introduction to the time of its withdrawal from the market, averages only about five years in the USA (Norwood and Smith, 197I) which means that the majority of drugs in current use were either unknown or unavailable when today's practising doctors were medical students. The problem for the medical profession is not so much one of improving education in drug therapy at medical school but one of developing efficient systems of continuing education.

Practitioners have several sources of information about drugs. There are professional sources such as articles in medical journals, recommendations from colleagues, professional society meetings, textbooks and postgraduate teaching. Official and governmental sources include the Department of Health and Social Security, the Prescribers fournal, the British Pharmaceutical Codex, the British National Formulary. The Consumer's Association produces the Drug and Therapeutic Bulletin. Drug companies provide practitioners with several sources of information through visits from representatives, sponsored postgraduate seminars, film shows, lunches and dinners, direct mail advertisements, advertisements in medical periodicals and booklets which may be sent direct or given by representatives. Commercial concerns produce controlled-circulation periodicals and drug compendia such as the Monthly Index of Medical Specialities (MIMS).

The purpose of this paper is not to assess which sources of information are used most or have the greatest impact but to discuss the quality of information from one particular source, advertisements for drugs. The question is, What kind of information appears in drug advertisements and how useful is it?

Drug companies spend between 12 and 40 per cent of sales on sales promotion, the amount depending on the country and the method of calculation (Hemminki, I975). The drug industry's total promotional budget in the UK is probably in the region of $£ 30$ to $£ 40$ millions and this expenditure includes the cost of sales representatives, courses, meetings, film shows, entertainment and direct mail and periodical advertisements. The money spent on direct mail and periodical advertisements in the UK cost the pharmaceutical industry an estimated $£ 6$ million in 1973 (Cowhig, 1974).

\section{The shape of the present study}

The data which will be discussed here come from a study of drug advertisements, conducted while the author was working at the Medical Sociology Research Centre at Swansea on a programme of research on prescribing and general practice. The study concentrated on advertisements appearing in 
periodicals and direct mail advertisements aimed at general practitioners. It is a relatively simple job to monitor advertising, and the monitoring and evaluation of advertisements reported here occupied the time of one research worker (the author) and a part-time research assistant.

Two samples of advertisements were monitored between October 1974 and March 1975. The first sample comprised all those periodicals that are regularly seen by general practitioners. Amongst these are the controlled-circulation periodicals which are sent free to all general practitioners. A few of these are drug company house journals, but the majority come from independent commercial enterprises. The number of controlled-circulation periodicals sent to general practitioners doubled from about 10 in 1966 to more than 20 by 1974 . Also monitored were the periodicals with large circulations to which general practitioners subscribed. The second sample was of advertisements sent directly to general practitioners: these were monitored with the help of 13 general practitioners in England and Wales who collected all their promotional mail for different weeks in the study period.

\section{Controls over drug advertisements}

Before considering the extent and content of drug advertisements it may be useful to review controls over drug advertising. Statutory regulation derives from the Medicines Act 1968 which provides that any commercially interested party who issues a false or misleading advertisement relating to medicinal products is guilty of an offence under the Act. Advertisements must not include recommendations for the use of the product other than those specified in the product licence under which the preparation is produced. The Act also requires that an advertisement may not be sent to a practitioner unless a data sheet is also sent or has been sent within the previous 15 months. The data sheet is meant to provide the practitioner with an objective statement, in a convenient form for reference, of essential particulars about the product (Department of Health and Social Security, 1968). Data sheet information has to be consistent with the product licence, and all advertisements for the product must be consistent with the data sheet and the licence.

The regulations also provide that the data sheet must be of a particular size, colour and weight of paper. The brand name must be no more than 2.25 times the size of type for other information. The name and address of the holder of the product licence must be given together with a description of the appearance and pharmaceutical form; the active ingredients described by their approved or monograph names; the quantity of each ingredient contained in each unit dose, or when there is no unit dose the percentage of each active ingrediento in the product; the pharmacological action and theT indications for which it is recommended; recom- $-\frac{5}{n}$. mended doses for adults and children; methods andes? routes of administration; contraindications; warnings; precautions; action to be taken in the event of an overdose; main side effects and adverse reactions? likely to be associated with the product; pharmaceut $\frac{}{\mathrm{D}}$ ical precautions; legal category; package quantities and product licence number. These requirements apply to data sheets only and do not apply tơn advertisements.

Most pharmaceutical manufacturers in the UKare members of the Association of the British $\vec{\sigma}$ Pharmaceutical Industry (ABPI) and voluntarys regulation of advertising derives from their coded of practice, which aims 'to secure the universaki acceptance of high standards of conduct in the marketing of medical products designed for useo under medical supervision' (ABPI, 1974a). The? code emphasizes that information should be presented to doctors in a form that conforms tow legal requirements and to 'professional standards of ethics and canons of good taste'. Acceptance and observance of the code are a condition of ABPI membership.

The code requires that an advertisement aimed ato providing a doctor with enough information on which to reach a decision for prescribing must give्్ the active ingredients using approved or other non $\frac{0}{\mathrm{D}}$ proprietary names contained in each unit dose; the recommended dose, method of use and route of administration; side effects, precautions and contra 3 indications; a statement that further information is available, and the company's name and address? When the advertisement is aimed only at remindings doctors of the availability and the main indication of a product or when 'it is ... obviously impracticable to display legibly the full information', the codeh requires as a minimum the approved or non- 3 proprietary names of the active ingredients, a statement that full prescribing information isavailable, and the company's name and address $\frac{7}{0}$ The basic cost of the product to the NationaE. Health Service must be given in all promotionafo literature except when such information would clearly be inappropriate.

\section{The general practitioner's typical postbag}

On average in each month during the period monitored general practitioners received 36 issues of controlled-circulation periodicals (see Appendix) and 30 envelopes containing direct mail advertise- $-\vec{D}$ ments (Stimson, 1960). This is a total of 66 postaP items in a typical month and an average of 2.6 postal items for each postal delivery day. An average day's post included at least one free controlled-circulation periodical and one direct maip advertisement. In addition, based on circulation 
figures, each general practitioner might also have received six issues of subscribed periodicals. In terms of the volume of material the unsolicited post far exceeds other material.

All periodicals devote large proportions of space to advertisements. In controlled-circulation periodicals an average of $\mathbf{4 2}$ per cent of pages is devoted to drug advertisements and 3.5 per cent to other advertisements. In the subscribed journals which were monitored (British Medical fournal, Practitioner, fournal of the Royal College of General Practitioners) 23 per cent of pages was devoted to drug advertisements and 23 per cent to other advertisements. Obviously the controlled-circulation periodicals rely on advertisements for revenue, but it would appear that subscribed journals also are heavily dependent on revenue from advertisements.

The average number of drug advertisements to which general practitioners were potentially exposed each month in the study period was 1331, an average of 53 advertisements for each postal delivery day. This was made up of an average of I I 7 advertisements in controlled-circulation periodicals, 174 in subscribed journals and 40 direct mail advertisements. We talk of potential exposure because this figure is calculated by adding every advertisement sent to general practitioners in the study period. Obviously practitioners do not examine every periodical page by page, nor is every direct mail envelope opened and the contents examined.

The main change in promotional activities in the last to years is the trend away from direct mail advertisements to advertisements appearing in controlled-circulation periodicals. In 1966 a survey conducted for the Committee of Enquiry into the Relationship of the Pharmaceutical Industry with the National Health Service (1967) found that each general practitioner received an average of seven items of promotional material each day. In recent years the amount of direct-mail advertising has been reduced. The ABPI reports that the average number of direct mail advertisements received by doctors was 3.7 items for each postal delivery day in 1972 and 2.7 in I973 (ABPI, 1974b). The reduction in direct mail has been more than replaced by the increase in controlled-circulation periodicals because of the large number of advertisements in each periodical. The number of mail items has reduced but the number of advertisements per day has risen from seven in 1966 to 53 in $1974 / 5$.

\section{Information content of drug advertisements}

The first question we asked about the content of advertisements was what information they contained and how much there was. To do this we made a subsample analysis of every unique advertisement which appeared in the periodicals for three months. When a drug was promoted in several different advertisements the different advertising copy in $\stackrel{\mathbb{Q}}{\stackrel{2}{ }}$ each was analysed. In all, 591 different advertisements for 316 drugs were examined (Stimson, 1975a).

First, advertisements were examined for information which would be of help to a doctor in deciding whether to prescribe the drug. The most common item of prescribing relevant information was a quantitative list of active ingredients of the drug preparation (in 43 per cent of advertisements). The next most common item was the recommended dose, although this appeared in only 14 per cent of advertisements. Contraindications, side effects and special precautions were mentioned in 4 per cent or fewer of advertisements. Only 6.3 per cent of all the advertisements gave the cost to the NHS of the drug preparation.

The overall finding is that these advertisements in periodicals contain little information which is relevant to prescribing. Taking as a minimum requirement some mention of any of the items of prescribing information mentioned above, 49 per cent of advertisements contained no prescribing information whatsoever. Looking at this the other way around and asking how many advertisements gave all of the above items of prescribing information, we found that only 0.5 per cent gave all this information. There were no appreciable differences in the amount of information given for different therapeutic classes of drug or in different journals. The first conclusion is that advertisements in periodicals rarely give information which would be of use to a doctor in considering whether to prescribe the drug preparation. It is worth noting that these advertisements are the most frequently occurring type.

For many years the DHSS and medical school teachers of therapeutics have encouraged generic prescribing. They have been relatively unsuccessful because approximately 70 per cent of prescriptions written by general practitioners are written by brand name (Parish, I97I). It is obviously im- ㄱ portant to drug companies to put the brand name $\frac{D}{0}$ prominently in advertisements. In the advertisements examined the brand name appeared between $N$ three and four times more often than the approved $N$ name (it was mentioned an average of 4.6 times in $N$ each advertisement). In one advertisement the brand $\omega$ name appeared 24 times. The average type size for brand names was $9 \mathrm{~mm}$ wide and for approved names $\stackrel{\varrho}{=}$

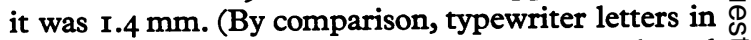
elite style are $2 \mathrm{~mm}$ wide.) So on average brand names were seven times the size of approved names. The legal requirement for data sheets limits the $\frac{P}{\mathbb{D}}$ brand name to no more than 2.25 times the size of $\frac{?}{8}$ the approved name. In some advertisements the $\stackrel{\mathbb{2}}{2}$ approved, or non-proprietary name, was hard to find, being hidden in the text, in the title of a $\delta$ reference article, or in small print. In 8 per cent of advertisements the approved name was absent

\section{年}


altogether. It is of note that the code of practice of the ABPI requires that the approved or nonproprietary name should always be present. Half the advertisements with no approved name were for drugs made by companies which were members of ABPI. These advertisements appeared in both subscribed and controlled-circulation periodicals.

Clearly advertisements for drugs in periodicals give very little information and generally do not provide enough for a practitioner to make a decision on whether to use the drug. This low level of information can hardly be due to problems of space or cost; comparing the typical entry in MIMS with the typical periodical advertisement, the typical entry in MIMS measures $26 \mathrm{~cm}^{2}$ and the typical periodical advertisement measures about $250 \mathrm{~cm}^{2}$ with a range from $50 \mathrm{~cm}^{2}$ to $1000 \mathrm{~cm}^{2}$. A MIMS entry has space for brand name, approved name and active ingredients, legal category, appearance, indications, cost to NHS, recommended dose and manufacturer's name, and may mention special precautions and contraindications. This is much more information than is found in advertisements.

What we do find is that although advertisements tend to have little useful prescribing information many devote space to product pictures ( 27 per cent), pictures of patients (34 per cent), pictures of diseases ( 9 per cent) and diagrams ( 6 per cent).

\section{References to further information}

Between a third and a half of drug advertisements give references to articles and papers which substantiate claims for products and provide the reader with a potential source of further information. A typical drug advertisement in a periodical has two or three such references backing a claim for the use of a drug preparation. These references are given in a style similar to those found in professional texts and should enable the reader to check on the claims in the advertisement. Indeed the ABPI code of practice (1974a) requires that information in promotional material must be capable of substantiation. We decided to look at the availability and content of these references in advertisements.

To see how easy it would be for the general practitioner reader to obtain copies of references given in advertisements it was decided to see whether the reference would be available in several different types of medical library. We chose a library at a postgraduate medical centre (with 33 periodicals), a library at a large general hospital (with 93 periodicals) and a library at a medical school (approximately I500 periodicals). A further indicator was based on the Library Association list (1973) of titles which are generally considered most likely to provide useful coverage, and is intended to be useful to all types of medical libraries. It lists approximately 250 periodicals.
Of the references mentioned in drug advertise $\stackrel{\mathbb{D}}{\Omega}$ ments, we excluded book references and found that 9 per cent of the remainder were not available because they were unpublished. The published? papers in journals were then checked for availabilit $\overrightarrow{\mathbf{F}_{\text {f }}}$ in the journal lists from the four types of library A further 18 per cent of the published references were not available in any of the four libraries, giving a total unavailability of reference articles of 26 pex cent. This limited survey of availability indicated that a general practitioner reader who tried to trace the references given in periodical advertisementş would find that 26 per cent were unavailable because they were unpublished or because the journal cited was not held in any of the four types of library examined; 29 per cent would be found in the post 5 graduate centre library, 43 per cent would be in the general hospital library, 57 per cent would be found in the Library Association list of periodicals and 74 per cent in the medical school library.

Most advertisements invite the reader to write for further information (this is a requirement of the ABPI code of practice). We therefore decided to see whether the references mentioned were available from the drug companies. Taking a sample of periodical advertisements with reference articles the drug companies concerned were requested by of general practitioner to supply copies of the refer ences cited in their advertisements. A photocopyo of the advertisement was sent with each letter The drug companies responded quickly, with mos? replying within two weeks of the original request. However, they supplied only 82 per cent of the references requested. This availability is higher than the availability from the libraries, but considering that the drug companies themselves cited the references one might have expected to receive alf the cited material. Some supplied more materiaB than requested, mainly data sheets, further refer-i ences and handouts.

Examination of the reference articles supplied allowed an assessment of their type and content. Some articles were laboratory studies, letters to medical journals, single case reports, surveys and trials of competing drugs. Sixty-three per cent of the articles referenced were some sort of clinicaln trial of the drug concerned. The clinical trials weren assessed according to the method of Mahon and ${ }^{\omega}$ Daniel (1964) for the assessment of reports of clinical trials which involves the stepwise application of the following criteria: presence of adequates controls, including the effects of placebo as well as standard therapy; randomization of treatments $; 0$ objective assessment of drug effects, including the $\vec{D}$ principle of the double-blind trial to avoid biased evaluations; statistical analysis of results. The ${ }^{\varrho}$ clinical trials were also assessed for indications of sponsorship by manufacturers. Two indicators were used: first whether the authors had chosen to refe? to the drug by its approved or chemical name ofô 
whether they had used the brand name; second, whether there was any mention of help from the drug company. A simple mention that the company supplied the authors with the drug was not deemed sufficient: we included only a statement of the drug company's help with organizing the trial, financial help, help with statistical analysis, supply of data forms or the involvement of a drug company's medical adviser in the conduct and authorship of the study.

Only 6 per cent of the total references were for clinical trials which were adequately conducted, and which had no mention of brand name and no obvious drug company involvement. Readers of drug advertisements would therefore be mistaken if they assumed that references in advertisements were for adequately conducted, independent clinical trials.

We found some inconsistency between drug companies' claims and the original text of the references, and quotations in advertisements were occasionally presented in a manner which tended to change the meaning of the original text. Sometimes separate quotations were linked together as if they had been consecutive in the original and simply shortened for convenience. Some of these quotations were not from the same paragraph in the original, and in one case a sentence from an early part of the original paper was linked to, and put after, a sentence from another part of the paper. It is hard to escape the conclusion that references in drug advertisements are included in order to give a respectable scientific appearance to the advertisement rather than for their scientific usefulness.

\section{Images and stereotypes ${ }^{1}$}

A simple quantitative analysis of the information content of advertisements misses much, for, like any other advertisement, the message of the drug advertisement is not only in the written information, but also in the overall 'image' conveyed. Advertisements may be seen as constructing a certain type of reality about the nature of a drug, the typical illness it is used to treat, a typical patient with the illness and typical causes of the illness. Here we are moving from a quantitative content analysis of the type suggested by Carney (1972) into methods which may be closer to that of the art or social critic. At this level the advertisement can be considered as a cultural phenomenon. For this we found it useful to draw on the work of Berger (1972) and Barthes (1973).

Part of the imagery is in the types of people who are portrayed for different types of problems and the way these people are portrayed. Several authors (Stimson, I975b; Prather and Fidell, 1975; Mant and Darroch, 1975) have independently noted the

\footnotetext{
1Some of the advertisements referred to in this section
} were published outside the monitoring period. sex stereotyping in drug advertisements in the UK, USA and Australia. Advertisements for psychotropic drugs more often show women than men thus reinforcing doctor's expectations that the patient requiring such a drug will be female. Advertisements for non-psychotropic drugs more often show men. Advertisements showing women and men are highly stereotyped as to sexual and social roles with women portrayed as mothers, wives and housewives, and men more likely to be portrayed as engaged in some paid occupation. Smith (1976) has shown that the elderly are generally portrayed in a negative way.

When we compared advertisements for the contraceptive pill with advertisements for tranquillizers and antidepressants, we found that different stereotypes of women were used for the different drugs. Advertisements for the contraceptive pill show a very select group of the female population. Few if any appear to be working class, none are shown as engaged in occupation at all - whether housework or paid employment. The women in the advertisements do little other than just relax or recline and stare into the distance or out of the photograph at the viewer. Background settings are either non-existent or show pleasant parks, gardens, grass and flowers. The women do not appear to live in a social environment, which focuses our attention instead on their own attraction. Most of the women look affluent and they are dressed in new, expensivelooking clothes. Their hair is well groomed. The likely candidate for the pill is unlikely to have children for there are rarely children in the pictures. Most of the women shown are at the younger end of the fertile years, none looks older than 35 and most of them give the impression of being in their 20s. The pictures show mainly married women for there is a wedding ring wherever a left hand is shown.

In contrast the women in tranquillizer and antidepressant advertisements are usually older and have children. They are not dressed and groomed for pleasure, rather they appear to be tired of the drudgery, boredom and loneliness of the woman's $\frac{7}{0}$ world. The woman's world in the tranquillizer advertisements is the house and shops. The $N$ 'harassed housewife' in a Limbitrol advertisement $N$ is at the sink, standing between the washing machine $N$ and a table cluttered with kitchen objects, with a $\omega$ nagging daughter by her side. An Integrin advertisement features a woman with a bowed head, $\stackrel{\circ}{\subset}$ holding a dishcloth, standing beside a pile of dirty dishes magnified more than life size.

The visual image of the problems of the woman's role is often very powerful. For instance an adver- $\frac{D}{\Phi}$

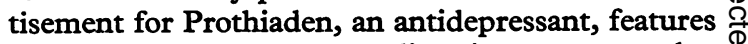
a sad-looking woman standing in a supermarket $\varrho$ with shelves of pet food on one side and shelves of $\bar{r}$ toilet rolls on the other. The simple message which $\delta$ sums up her situation is: 'Emotional distress:음 first-line therapy Prothiaden'. 
Cultural clichés of anxiety and depression are used. One advertisement specifically draws attention to features of the patient's appearance and claims that there are certain visible signs which suggest anxiety and depression. These are: 'some attempts at make-up', 'respectable facade, ie, hat, handbag, gloves and even necklace'. Among the signs suggestive of depression are: 'tired, shadowed eyes/ pale complexion', 'outmoded lipstick, poorly applied'. The verbal clichés are also used such as, 'I just can't cope, Doctor'. This sort of imagery would appear to encourage the 'snap' or 'at-aglance' diagnosis, and does not encourage further examination of the woman's problem.

Analysts of advertisements have also drawn attention to the imagery which translates social, economic and political problems into medical problems (Stimson, 1975c; Lennard et al, 197I). Overcrowding, traffic congestion, bereavement, loneliness, political protest, industrial action, personal finances, marriage, going to college are portrayed in drug advertisements in terms of the individual stress which may be associated with them. Zola (1972) describes this medicalization as occurring by "making the labels "healthy" and "ill" relevant to an ever-increasing part of human existence'. Lennard et al (197I) describe it as 'redefining and relabelling as medical problems calling for drug intervention a wide range of human behaviours which, in the past, have been viewed as falling within the bounds of the normal trials and tribulations of human existence'. Indeed the implicit image of some tranquillizer advertisements is that the state of living in the world today is enough to generate problems for everyone. In one advertisement Librium is shown to have a clear place in promoting world happiness. A photograph of a demonstrator kicking a policeman, a photograph taken at an anti-Vietnam war demonstration in London and which featured in many national newspapers, is accompanied by this message:

'It is ten years since Librium became available. Ten anxious years of aggravation and demonstration, Cuba and Vietnam, assassination and devaluation, Biafra and Czechoslovakia. Ten turbulent years in which the world-wide climate of anxiety and aggression has given Librium - with its specific calming action and its remarkable safety margin - a unique and still growing role in helping mankind meet the challenge of a changing world.'

This interpretation of the content of drug advertisements implies that there are implicit images which are important to consider in addition to the written scientific information which is (or, as we have shown, usually is not) given. We need to look at the total message shown by advertisements. Analyses of advertisements for different groups of products show that they portray a consistently limited and stereotyped view of the world.

\section{Conclusions}

The problem with drug advertisements as a source of therapeutic information is that they provide? hardly any therapeutic information. Analyses of $\vec{F}$ drug advertisements indicate that they are limited $\stackrel{\text { ? }}{?}$ as vehicles for providing scientific information about $\frac{\mathrm{C}}{\mathrm{O}}$ the usefulness of drugs. They are an inefficient use $\frac{\bar{c}}{\mathrm{c}}$ of space if the aim of the advertisement is to $\overrightarrow{\mathbb{D}}$ provide information to doctors who might prescribe $\varrho$ the drug preparation. Possibly the low level of is information has arisen because companies now rely $\overrightarrow{0}$ on the data sheet, but without a comparison with earlier practices this cannot be known. What is $\vec{\omega}$ certainly the case is that data sheets need to be sent to practitioners only every 15 months, whereas the average general practitioner is potentially exposed $\omega$ to 1300 advertisements each month. As Abel-Smith $-\vec{v}$ (1976) has drawn to our attention, the promotionalo activities of the drug companies are a costly way of ${ }_{-}^{\supset}$ informing doctors about drugs. He suggests that $\vec{z}$ the total sales promotional activity in the UK would make it possible for each general practitioner $\mathcal{S}$ to have a teacher of medicine or therapeutics spend $\vec{\varphi}$ about a month a year working with him in his $\checkmark$ practice giving him advice. A month would be much ${ }^{-}$ more than required to inform a doctor about the handful of really valuable new preparations produced each year.

Self regulation and monitoring by the $\operatorname{drug} \stackrel{0}{\frac{D}{\varnothing}}$ industry does not seem to be effective. For example, $\varrho$ the basic cost to the NHS is given in only 6 per $\overrightarrow{\overrightarrow{0}}$ cent of advertisements although the ABPI code 3 requires that it must be given in all promotional literature except when such information would clearly be inappropriate. From the size of the advertise- $\overline{3}$ ments the omission of cost cannot be due to space $\mathbb{Q}$ problems, and as most of the controlled-circulation periodicals are limited to a UK circulation, the reason for the omission cannot be because the $\frac{O}{3}$ advertisements will be seen in other countries. As

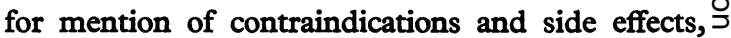
the drug industry appears to include the minimum $\frac{D}{O}$ necessary under governmental regulations. Side effects which are required to be listed under the $N$ US Food and Drug Authority Regulations are not $N$ acknowledged by the same companies in Britain $N$ (Parish, 1976). A recent survey of the situation in $\omega$ Latin America showed that companies frequently? minimize risks and exaggerate claims for their drugs ${ }_{C}$ in ways not permitted in the USA. Drugs are recommended for a wider variety of conditions :than allowed for in the USA and warnings on ${ }^{\circ}$ restrictions of use and adverse reactions are in- $\frac{\vec{D}}{\mathbb{D}}$ complete or entirely absent (Haslemere Group, $\stackrel{?}{\oplus}$ 1976). One step towards improving the quality of $\propto$ promotional material would be to establish indepen dent monitoring of drug advertisements. This is $O$ relatively easy and it is perhaps surprising that the medical profession has not taken this task upon itself 


\section{References}

Abel-Smith, B. Value for Money in the Health Services. London, Heinemann, 1976.

Association of the British Pharmaceutical Industry (1974a). Code of Practice for the Pharmaceutical Industry. London.

Association of the British Pharmaceutical Industry (1974b). ABPI News, 15, I.

Barthes, R. Mythologies. London, Paladin, 1973.

Berger, J. Ways of Seeing. London, Penguin, 1972.

Carney, T F (1972). Content Analysis. London: Batsford.

Committee of Enquiry into the Relationship of the Pharmaceutical Industry with the National Health Service (1967). London: HMSO.

Cowhig, J (1974). General Practitioner, 4, Ir.

Department of Health and Social Security (1968). Medicines Act 1968, Notes on Data Sheets. MAL25, London: DHSS.

Haslemere Group. Who needs the drug companies? London, Haslemere Group and War on Want, 1976.

Hemminki, E (I975). Review of literature on the factors affecting drug prescribing. Social Science and Medicine, 9, III-II5.

Lennard, H, Epstein, L J, Bernstein, A, and Ransom, D C. Mystification and Drug Misuse. San Francisco, Jossey-Bass, I97I.

Library Association (I973). Books and periodicals for medical libraries in hospitals.

Mahon, W A, and Daniel, E E (1964). A method for assessment of reports of drug trials. Canadian Medical Association fournal, 90, 565.

Mant, A, and Darroch, D B (1975). Media images and medical images. Social Science and Medicine, 9, 613-8.

Norwood, G J, and Smith, M C (197I). Market mortality of new products in the pharmaceutical industry. Fournal of the American Pharmaceutical Association, II, 592.

Parish, P (197I). The prescribing of psychotropic drugs in general practice. Fournal of the Royal College of General Practitioners, Supplement 4, vol 2 I.

Parish, P A (1976). Personal communication.

Prather, J, and Fidell, S (1975). Sex differences in the content and style of medical advertisements. Social Science and Medicine, 9, 23-6.

Smith, M C (1976). Potrayal of the elderly in prescription drug advertising. The Gerontologist, 16, 329-334.
Stimson, G V (1975a). Information contained in drug advertisements. British Medical fournal, 4, 508-9.

Stimson, G V (1975b). Women in a doctored world. New Society, 32, $265-7$.

Stimson, G V (1975c). The message of psychotropic drugs ads. Fournal of Communication, 25, $153-60$.

Stimson, G V (1976). The extent of advertising for pharmaceutical products. In, Prescribing in General Practice, Parish, P A, Stimson, G V, and Mapes, R E A (eds). Fournal of the Royal College of General Practitioners, Supplement, no I, 26, 69-76.

Zola, I K (1972). Medicine as an institution of social control. Sociological Review, 20, 487-504.

\section{Appendix}

Controlled circulation (ie, free) periodicals received by general practitioners from October 1974 to March 1975

Pulse

Doctor

Medical News

Medical Week (ceased November 1974)

General Practitioner

World Medicine

Update

Modern Medicine

Medical Digest

MIMS (Monthly Index of Medical Specialties)

MIMS Magazine

Modern Geriatrics

Practice Team

Medicine

Interface

Pulse magazine

Patient Care

Update Review (started January 1975)

British Fournal of Sexual Medicine

$B M A$ News

MIMS colour index

Rostrum (Pfizer)

Documenta Geigy 